Article

\title{
Primary and Albedo Solar Energy Sources for High Altitude Persistent Air Vehicle Operation
}

\author{
Tim Smith ${ }^{1, *}$, Michele Trancossi ${ }^{2}$, Dean Vucinic ${ }^{3}$, Chris Bingham ${ }^{1}$ and Paul Stewart ${ }^{4}$ \\ 1 School of Engineering, University of Lincoln, Brayford Pool, Lincoln LN6 7TS, UK; cbingham@lincoln.ac.uk \\ 2 Department of Engineering and Mathematics, Sheffield Hallam University, City Campus, Howard Street, \\ Sheffield S1 1WB, UK; M.Trancossi@shu.ac.uk \\ 3 Department Mechanical Engineering, Vrije Universiteit Brussel (VUB), Pleinlaan 2, B-1050 Brussel, Belgium; \\ dean.vucinic@vub.ac.be \\ 4 College of Engineering and Technology, University of Derby, Kedleston Rd, Derby DE22 1GB, UK; \\ p.stewart1@derby.ac.uk \\ * Correspondence: tismith@lincoln.ac.uk; Tel.: +44-1552-8000
}

Academic Editor: Francesco Calise

Received: 15 November 2016; Accepted: 10 April 2017; Published: 22 April 2017

\begin{abstract}
A new class of the all electric airship to globally transport both passengers and freight using a 'feeder-cruiser' concept, and powered by renewable electric energy, is considered. Specific focus is given to photo-electric harvesting as the primary energy source and the associated hydrogen-based energy storage systems. Furthermore, it is shown that the total PV output may be significantly increased by utilising cloud albedo effects. Appropriate power architectures and energy audits required for life support, and the propulsion and ancillary loads to support the continuous daily operation of the primary airship (cruiser) at stratospheric altitudes (circa $18 \mathrm{~km}$ ), are also considered. The presented solution is substantially different from those of conventional aircraft due to the airship size and the inherent requirement to harvest and store sufficient energy during "daylight" operation, when subject to varying seasonal conditions and latitudes, to ensure its safe and continued operation during the corresponding varying "dark hours". This is particularly apparent when the sizing of the proposed electrolyser is considered, as its size and mass increase nonlinearly with decreasing day-night duty. As such, a Unitized Regenerative Fuel Cell is proposed. For the first time the study also discusses the potential benefits of integrating the photo-voltaic cells into airship canopy structures utilising TENSAIRITY ${ }^{\circledR}$-based elements in order to eliminate the requirements for separate inter-PV array wiring and the transport of low pressure hydrogen between fuel cells.
\end{abstract}

Keywords: airship; photovoltaics; albedo; cloud albedo; persistent air vehicle

\section{Introduction}

Whilst the concept of a feeder-cruiser arrangement for airships is not entirely novel, the projected scale and operating altitude of the proposed Multibody Advanced Airship for Transport (MAAT) [1] is unprecedented. Operation is based on large-scale 'cruiser' airships that persistently operate at high altitude (around 15 to $18 \mathrm{~km}$ ), with operational air speeds of up to $200 \mathrm{~km} / \mathrm{h}$, on global routes along which there exist exchange points where smaller 'feeder' craft are able to dock in order to transfer passengers and freight from either ground-based stations or other locally operating cruiser airships. The MAAT concept is for a large, all electric dirigible airship, of triaxial ellipsoid geometry approximately $400 \mathrm{~m}$ long, $240 \mathrm{~m}$ wide and $80 \mathrm{~m}$ deep [2,3], depicted in Figure 1, showing the cruiser with two feeders docked within the structure. The underlying design concept is to have multiple feeders docking with the cruiser whilst in flight, transferring passengers and cargo. The paper will concentrate on the "all electric" nature of the cruiser and its significant energy requirement with 
a particular emphasis on solar harvesting and how additional or auxiliary energy may be harvested from the underside surfaces due to the various albedo effects, specifically cloud top albedo, providing a useful source of supplementary energy. This technique could be applied to any persistent high altitude air vehicle that operates above typical cloud top levels.

Historically, airships were the first aircraft to be powered using electric propulsion and to therefore perform zero emission flights, as demonstrated by Albert and Gaston Tissandier in 1883 [4]. In 1978, Khoury described a theoretical solar powered airship in New Scientist [5] capable of "dark hour" operation through stored energy, with a maximum speed of $80 \mathrm{Km} / \mathrm{h}$ and a relatively low operating altitude of $1 \mathrm{~km}$. Khoury also considered utilising the ground albedo as an important and supplementary source of energy. However, to date, cloud top albedo has not been considered for stratospheric altitude operation.

High Altitude Airships (HAAs) such as proposed by the NASA Langley Research Center [6] typically have a specific area covered in PV cells. The airship is then operated to ensure that the PV is, where possible, optimally aligned to the sun to maximise PV output. Continuous aircraft operation at high altitude has also been demonstrated using QinetiQ's Zephyr UAV (Unmanned Air Vehicle), which is solar powered and designed for continuous operation at altitudes of $18 \mathrm{~km} \mathrm{[7]} \mathrm{and} \mathrm{more}$ recently by the very successful Solar Impulse manned aircraft [8].

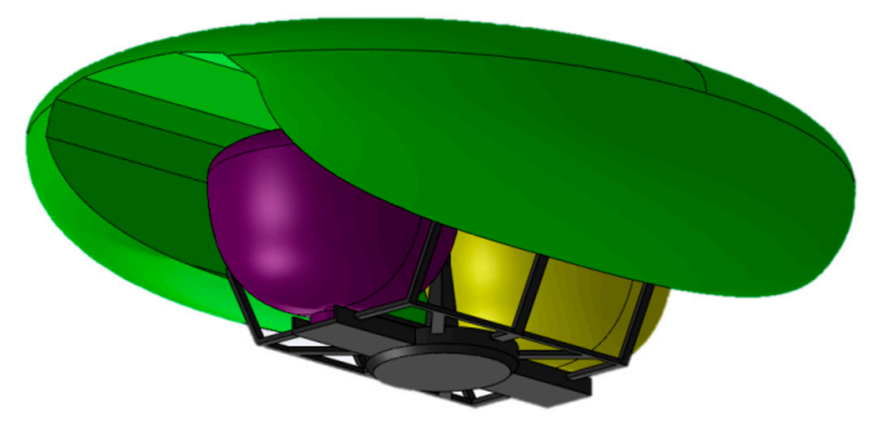

Figure 1. MAAT Cruiser-Feeder Concept.

The primary energy source for the MAAT is through harvesting sunlight from photovoltaic arrays mounted on the airship upper canopy surface to provide sufficient power during the day to operate the airship's systems, provide life support, propulsion and control, whilst producing sufficient excess energy that can be stored to facilitate continuous MAAT operation at 'night'. The excess energy is stored in the form of molecular hydrogen $\left(\mathrm{H}_{2}\right)$ and oxygen $\left(\mathrm{O}_{2}\right)$, obtained through electrolysing water stored on the airship (this is assumed to be a closed system; however, unavoidable losses are replenished by the feeders during passenger and freight exchanges as and when necessary), batteries and super-capacitors (SCs). The majority of the energy is stored as hydrogen (high energy density) and the batteries and SC's provide relatively high power density storage for short-term, high energy demands associated with propulsion. Electrically-powered operation during "dark hours" is obtained through the use of fuel cells using the stored hydrogen and oxygen. The effects of utilising a Unitized Regenerative Fuel Cell are also considered when compared to individual electrolyser and fuel cells along with a distributed modular power architecture.

As with any air vehicle, but especially air ships, the high altitude vehicle surface area is determined by the structure's shape and it is not easily increased without significantly impacting other design aspects; it is also a design aim of airships to maximise the volume to surface area ratio for both technical and commercial reasons, and this equally applies to the MAAT concept. It is also a requirement that enough additional energy is harvested during the "daytime" period to maintain systems during the "nighttime" for all seasons and operational latitudes of the MAAT system. It is therefore important that MAAT efficiently utilises the available surface area when considering the seasonal changes in day length and the many electrical loads required for passenger operations. 
The spectrum and intensity of the incident radiation at high altitudes are different to both terrestrial and space environments (where the majority of current data relates) due to the lower air mass above the PV panels. The study considers the nature of the spectrum at these altitudes as it is closer to the Satellite Peak Power (SPP) Glaser [9] as less infra-red absorption is apparent. The extinction factor for each wavelength range in the American Society for Testing and Materials International publication ASTM E490 [10] is produced and a model of the spectrum produced for any altitude reflecting the lower Air Mass encountered at high altitudes.

Notably, current research on climate warming has shown that the earth's total albedo has a daily average in excess of 30\% which has been verified through projects such as NASA's Clouds and the Earth's Radiant Energy System (CERES) and reported by Trenberth et al. in his article for American Meteorological Society [11]. Consideration is therefore given to fully covering the surface of the airship with photovoltaic panels in order to make use of both the earth's albedo and cloud top albedo which can exceed $90 \%$ for some common cloud types. It is important that such an approach is, if possible, mass neutral, and this can only be achieved by adopting air-beam construction techniques as described by Sunol et al. [12] which have the capability to integrate structural and electrical components along with low mass flexible PV films, thereby offering a potentially mass neutral solution.

Here, the paper focuses on the cruiser's ability to efficiently harvest as much energy as practicably possible to maintain operation during the longer winter nights when total solar irradiance due to the earth's declination is at its lowest. This is of paramount importance to the overall success of such a system if it is to compete with other transport counterparts. It is also shown that other persistent air vehicles, particularly unmanned, can benefit from harvesting cloud top albedo.

Previous studies by Dumas et al. [13] and Trancossi et al. [14] have considered the energetic design for such an unconventional airship with an emphasis on the operational energetic requirements at stratospheric altitudes of $15 \mathrm{~km}$ to $18 \mathrm{~km}$. As the airship operates continuously at these altitudes with no other source of energy other than that provided by the sun, it is clearly evident that consideration has to be given to the required energy consumption in any $24 \mathrm{~h}$ period, the length of day and the impact that day length has on the required amount of energy harvested. It is clearly evident that the airship cannot operate at latitudes where the day length is too short to harvest adequate energy for night time operations. The airship shape is also critical for the purposes of energy harvesting, where a large surface area is required. However, a large surface area with respect to the enclosed volume is not effective from either a technical or economic perspective due to mass, stability, drag and cost of materials. The adopted methodology is therefore to undertake an energy audit to determine the requirements for life support and propulsion based on available commercial equipment, determine operational day lengths, and investigate the impact on the required energy harvesting. Computer-based analysis using well established data for terrestrial and extraterrestrial irradiation, is used to predict both the direct and albedo sourced energy for harvest along with data from climate studies considering the impact of global warming and the earth's global energy budget. Consideration is then given to the airship's shape and how this would impact energy harvesting of both direct and indirect (albedo) solar energies as primary and auxiliary sources of electrical power.

\section{Energy Requirements and Availability}

\subsection{Energy Harvesting Audit}

It is estimated that the MAAT cruiser, the airship, requires a minimum mean sustainable operating power of 0.5 MW for life support and other functions (avionics, lighting, hotel, etc.) and an estimated 19.5 MW for propulsion only (depending on prevailing wind and altitude). A simplified power audit for the cruiser is given in Table 1 Power Audit of the MAAT Cruiser, based on Pallet [15] and other empirical calculations from aircraft data. This details the actual power requirements of the various systems that need to be met by the photovoltaic energy harvesting and storage systems. A number of loads such as the Environmental Control Systems (ECS), In Flight Entertainment (IFE), cabin lighting 
and galley size are directly governed by the total number of passengers (circa 260 for this study, though the number of passengers and freight ratio can be varied) and have therefore been scaled from various manufacturers and supplier's data and factored accordingly Majeed [16], Dornheim [17] and SkyPower [18].

It is clear that the second largest, and considering the altitude most critical load, is presented by the ECS, which maintains cabin pressurisation, air quality and temperature (comfort) control. Flight controls and emergency lighting are also critical (i.e., Catastrophic or Hazardous) with the remaining loads being considered non-critical (i.e., Major or Minor with regard to their effect on passenger safety). It should be noted that they represent the functional power requirements and do not reflect the number of redundant systems that may be necessary to meet safety requirements. Galley loads, beverage heating and chilling, are also currently considered as electrical at present, but they are ultimately expected to be supported from waste heat produced during operation of the electrolysers, fuel cells and other equipment, if practicable.

Table 1. Power Audit of the MAAT Cruiser.

\begin{tabular}{cc}
\hline Cruiser Load & Power (kW) \\
\hline Propulsion & $\sim 19.5 \mathrm{MW}$ \\
& $(72$ Pods—rated at circa $270 \mathrm{~kW}$ each) \\
\hline Control Systems & $100 \mathrm{~kW}$ \\
\hline Environmental Control Systems & $260 \mathrm{~kW}$ \\
$(1 \mathrm{~kW}$ per pax $)$ \\
\hline Avionic Systems & $10 \mathrm{~kW}$ \\
\hline Lighting & $7.6 \mathrm{~kW}$ \\
\hline In Flight Entertainment & $26 \mathrm{~kW}$ \\
\hline Galley & $60 \mathrm{~kW}$ \\
\hline Situational Awareness & $10 \mathrm{~kW}$ \\
\hline Energy storage ${ }^{1}$ & $\begin{array}{c}\text { Sized for maximum conversion day night scenario } \\
\text { (The electrolyser represents a significant mass and } \\
\text { will be sized on the predicted excess energy if any) }\end{array}$ \\
\hline Total & $20 \mathrm{MW}$
\end{tabular}

${ }^{1}$ Energy storage is recorded as, in effect, it is a load rated such that after system efficiencies in both conversion to and from hydrogen to electricity, there is sufficient energy stored to supply the required total power for the dark period.

A baseline power requirement exists that is independent of the airship's use (i.e., passenger, freight or mixed) and a load that is directly proportional to the passenger numbers, of which the life support system (or ECS) contributes the greatest component.

\subsection{Day Length}

The operational day length is derived from the airship's latitude and longitude and the earth's declination (see Equation (4) - where day length is determined by setting the sun's azimuth to $90^{\circ}$ ) and is shown in its typical graphical form in Figure 2. As the MAAT cruiser is to be operated in the higher and lower latitudes, the day length will vary accordingly, and it is not anticipated that the system will operate in locations where day length will be less than 6 hours, latitudes greater than $55^{\circ}$ north (or the southerly equivalent), although some unmanned missions could conceivably go beyond this if such a persistent air vehicle were used for communications, surveillance or scientific purposes. This is important since there is, on average, significantly greater cloud density at the higher and lower latitudes for albedo harvesting. During operation with long daylight hours where significantly more energy is available than is required for operation and storage, load banks are typically required to 
dissipate excess energy. However, in such instances, the load banks would be better replaced by additional storage and a seasonal cycle for energy storage capacity considered.

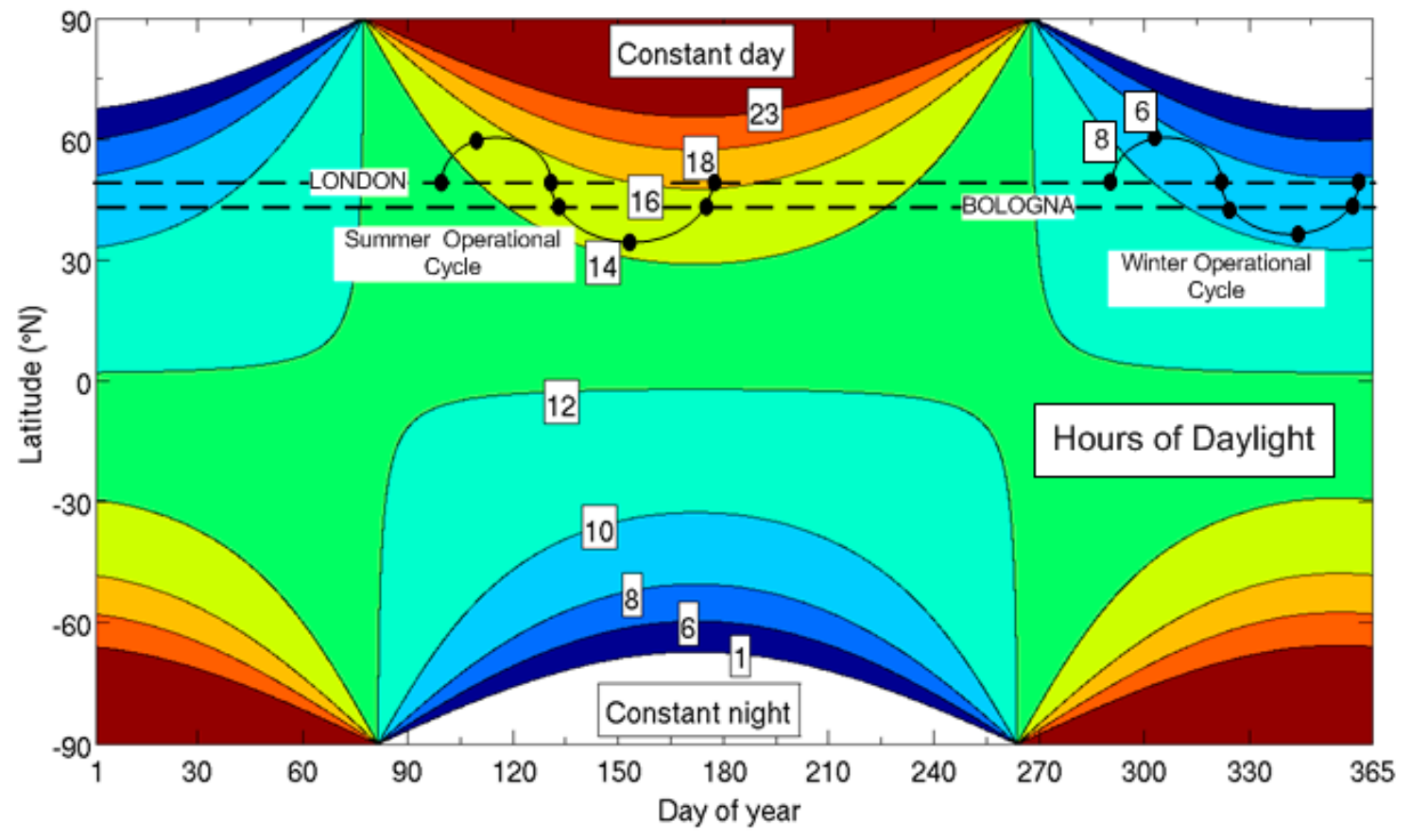

Figure 2. Operational Day Length.

\subsection{Impact on System Energy Requirement due to Day Length}

Figure 3 shows the required power/energy flow requirements for day night operation to facilitate continuous operation throughout the 'night' using stored energy from excess energy harvesting. The process of water electrolysis is assumed $50 \%$ efficient, as is the recombination of hydrogen and water in the fuel cells (this is considered typical of Polymer Exchange Membrane (PEM) technology which, to date, is the most promising solution) when combined in Unitized Regenerative Fuel Cells as proposed by Burke [19].

Assuming that night operation requires the same average continuous power as daytime operation, then the amount of energy stored must meet the night time consumption over the period of darkness. The energy audit determined that an average continuous power of $20 \mathrm{MW}$ is required for the airship. The National Renewable Energy Laboratory (NREL) [20] predict future PV efficiencies of $\sim 40 \%$ which would require an average incident solar power of $50 \mathrm{MW}$. Including the requirement for night time operation (assuming a 12 hour day) with energy storage conversion efficiencies of $25 \%$ ( $50 \%$ conversion to the storage medium of $\mathrm{H}_{2}$ and $\mathrm{O}_{2}$ and $50 \%$ conversion back to electric power which will result in an overall efficiency of $25 \%$ ) the required average incident solar power is then $250 \mathrm{MW}$. This assumes maximum continuous operation. If the life support systems only are considered, the continuous power requirement is $0.5 \mathrm{MW}$ and an average incident solar power of $6.25 \mathrm{MW}$ is required.

Losses associated with the electrical wiring and power conversion have been factored into the gross power figures and an analysis of the mass implications for the electrolyser, energy storage $\left(\mathrm{H}_{2}\right.$ and $\left.\mathrm{O}_{2}\right)$ and $\mathrm{PV}$ array with respect to varying day lengths, which are themselves determined by the operational latitude and time of year. The results are presented in Figure $4 \mathrm{a}-\mathrm{c}$ for the electrolyser, fuel cell and photo-voltaic array masses. These figures are based on current technologies used in aerospace applications with the photovoltaic mass being based on a-Si:H with a polyimide substrates and/or CORIN ${ }^{\circledR}$ XLS Polyimide (NeXolve Corporation, Huntsville, AL, USA) front optical film, as used in space applications. 


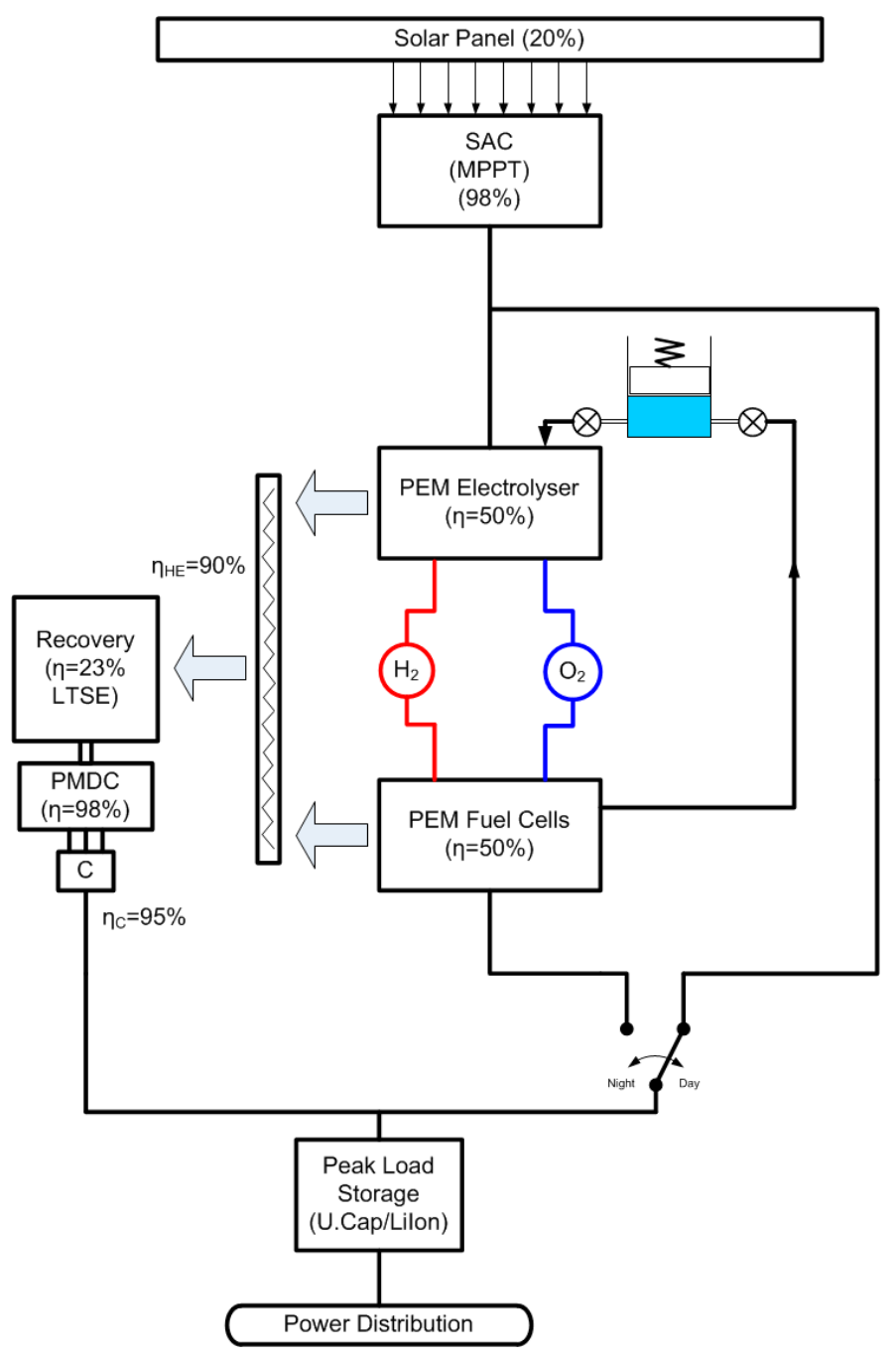

Figure 3. Energy Flow for day and night operation.

Of particular note is that the electrolyser size is determined by the day-night cycle whilst fuel cell mass is determined by the load and is constant at around $3.17 \mathrm{~kg} / \mathrm{kW}$. From the primary energy audit, it is clear that the electrical power can be significantly reduced by reducing the propulsive power. It should also be noted that under freight operation, there would be a minimum crew, if any, and therefore minimal or no requirement for life support systems, Smith et al. [21]. Also, in this scenario, operational stability (ride quality) could also be reduced, further reducing the power requirements. The cruiser can also exploit differing wind direction speeds at different altitudes and use flexible journey times. When passengers are included, the power requirements increase dramatically. It is also evident that a fixed area of the PV array and the power distribution mass are a function only of the load, with the remainder being a function of the Day/Night cycle. It is therefore critical to locate the electrolyser system components as close to the PV arrays as possible to minimise power system connections and losses.

Initial studies have assumed a separate electrolyser and fuel cell system. However, a Unitized Regenerative FC would allow better utilisation of mass, and although less efficient at converting energy to hydrogen and back, would offer a better system level efficiency Burke [19]. 
Photovoltaic Array Mass

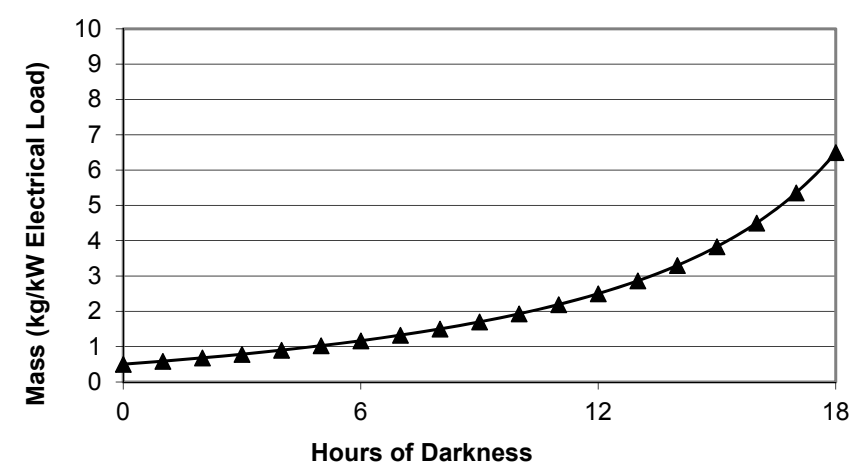

(a)

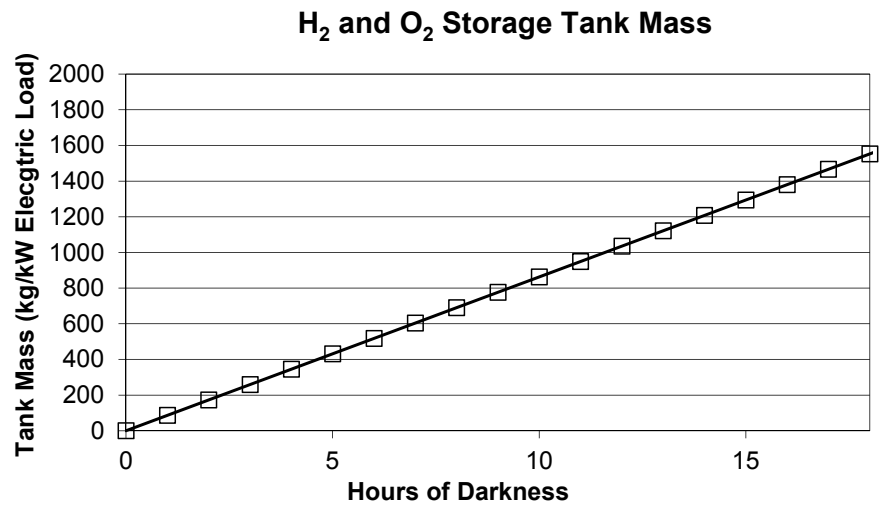

(b)

Electrolyser Mass

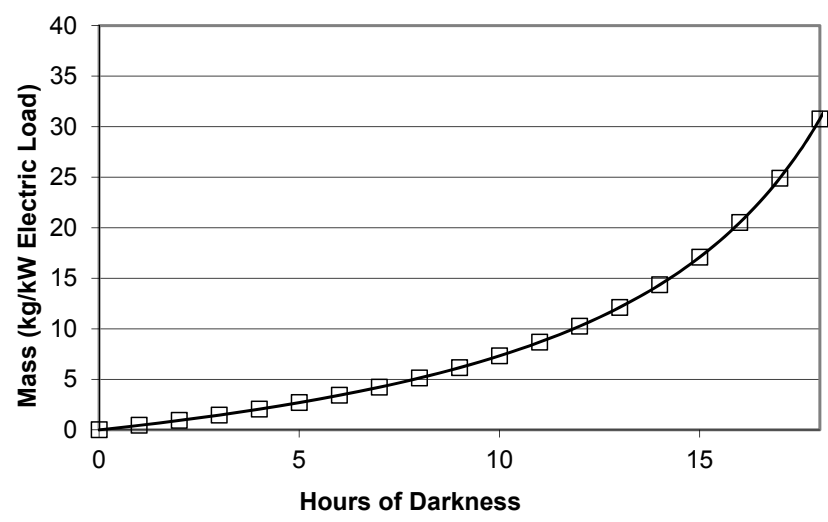

(c)

Figure 4. (a) Photovoltaic array mass required per kW Electrical Load for varying day lengths; (b) Hydrogen and Water storage tank mass required per kW Electrical Load for varying day lengths; (c) Electrolyser mass required per kW Electrical Load for varying day lengths.

\subsection{Energy Harvesting at Stratospheric Altitudes}

The load analysis has provided baseline power requirements for operation of the cruiser. To determine the viability of the MAAT System, it is necessary to determine the levels of energy that could be potentially harvested through photovoltaics. 
Consideration of high altitude air vehicles utilising solar power have typically focused on the direct effects of solar radiation in determining the available energy for harvesting. This has resulted in the PV arrays being mounted on the upper surface of the air vehicle. To ensure the optimum rate at which energy is harvested requires careful flight path planning, ensuring the best orientation of the airship to the sun. This also ensures that the mass of the PV systems can be minimised. This is acceptable for unmanned missions which are required to remain in a fixed operational zone, but it is not acceptable for passenger or freight operations. Manned operation, as shown in the previous section, requires significantly more power for propulsion, life support and general hotel functions. The power generation capability for the current MAAT is a function of the total upper illuminated surface area and significant work has been undertaken to optimise the shape to meet the requirements for a suitably large surface area for PV's whilst allowing passenger and freight operations. Increasing the surface area of the airship is not desirable as any increase in the surface area results in an increase in mass and therefore volume, which in turn increases the propulsion power. The alternatives are therefore to increase the energy efficiency or find an alternative source of energy. Previously reported research, particularly regarding the effects of global warming, e.g., Trenberth et al. [11], have identified that the total reflected Solar Radiation, albedo for the earth is $101.9 \mathrm{Wm}^{-2}$ which represents $29.8 \%$ of the total incoming average Solar Radiation of $341.3 \mathrm{Wm}^{-2}$. Furthermore, $79 \mathrm{Wm}^{-2}, 23.2 \%$, of the reflected energy is due to clouds and atmosphere with certain cloud types reflecting in excess of $60 \%$ and in some cases as much as $90 \%$. These figures are based on the earth's annual average Global Energy Flows. The incoming solar radiation is therefore the total solar radiation falling on the earth, which is represented by a shadow projected onto a plane surface orthogonal to the sun's rays of area $\pi r_{e}^{2}$, where $r_{e}$ is the earth's radius multiplied by the solar constant, $S=1365.2 \mathrm{Wm}^{-2}$ divided by the total surface area of the earth, i.e., $4 \pi r_{e}{ }^{2}$ (note: the solar constant varies, but the annual mean value used here is from Trenbeth [11] for 2009 at $1365.2 \mathrm{Wm}^{-2}$. A value of $1366 \mathrm{Wm}^{-2}$ is used elsewhere which is the long term average value used in ASTM E490-00A [10]). Presently, there is only sparse data available relating to the use of such energy for PV systems at stratospheric altitudes; however, considerable data does exist regarding the earth's albedo effect and the overall energy reflected back into space, particularly as a result of studies into the effects of global warming. The data referred to in the following sections are consolidated from the following sources: Liou [22], Donhoe [23] and Blumthaler [24] and their effects inferred with respect to PV systems. The analysis concentrates initially on direct solar energy harvesting and the modification needed for conventional terrestrial models as the thinner atmosphere at higher altitude has a reduced effect on the attenuation of the sun's radiation. The indirect effect of cloud albedo is then considered.

\subsubsection{Harvesting of Direct Insolation}

There is significant literature and data available for the spectra and irradiance of solar energy at terrestrial altitudes, Mean Sea Level (MSL) up to an altitude of $3 \mathrm{~km}$, and at the practical limit of the earth's atmosphere (Top of Atmosphere-TOA) given by Glaser [25] as the SPP constant. Dumas and Trancossi $[13,14,25]$ have also provided detailed analysis of the available energy at stratospheric altitudes and the effectiveness of conversion to hydrogen at these altitudes. The available spectral energy for MAAT will be governed by the total Air Mass (AM) between the air vehicle and the TOA along the incoming sun's ray path. Currently, the spectral energy is presented for extraterrestrial and terrestrial (at sea level) in ASTM E490-00a [10] and ASTM G173-03, respectively [26]. These have been compiled from experimental measurements from satellite- and ground-based measurements. It is normal to specify terrestrial PV systems for operation at AM1.5 that is an atmosphere 1.5 thicker than the atmosphere directly above, representing the average sun's attitude. AM1.0 represents the situation where the atmosphere thickness is directly overhead. The very high operating altitude of the cruiser means that only a maximum of $11 \%$ of the effective atmospheric mass lies above it, requiring a redefinition of the available spectral irradiance at this altitude. The impact on the solar spectrum at such altitudes is far less than at sea level, and the resultant spectral data with this lower air mass will 
need to be defined, and at some stage, verified experimentally. The new definition of Air Mass values for MAAT are given in Figure 5. The format for values of AM referenced to MAAT are, for example, AM1 $1_{\text {MAAT }}$, AM1.5MAAT, etc.

To calculate the irradiance at differing altitudes for different AM referenced to the MAAT altitude, Beer's law is used. The basic form is given in Equation (1):

$$
I_{\lambda(h)}=I_{\lambda(0)} e^{-\beta_{e} h}
$$

where

$I_{\lambda(h)}$ is the intensity of the light beam after passing through the medium

$I_{\lambda(0)}$ is the original light beam intensity

$\beta_{e}$ is the extinction coefficient over the medium thickness $h$.

To calculate transmissivity, $\beta_{e} \Delta h$ for each distinctive layer of the atmosphere Liou [27], Rapp-Arraras [28] need to be determined to give the total extinction, as in Equation (2). Alternatively, Aglietti [29] shows that a global extinction coefficient of 0.32 can be derived using standard test conditions since the SPP is known at the TOA, $1366 \mathrm{Wm}^{-2}$, and the AM1.5 direct beam component at MSL; $850 \mathrm{Wm}^{-2}$ is specified for testing PV panels.

$$
\alpha_{I N T}=\sum\left(\beta_{e} \Delta h\right)
$$

where:

$\alpha_{I N T}$ is the total extinction across the whole airmass

$\beta_{e}$ is the extinction coefficient over a section of atmosphere $\Delta h$.

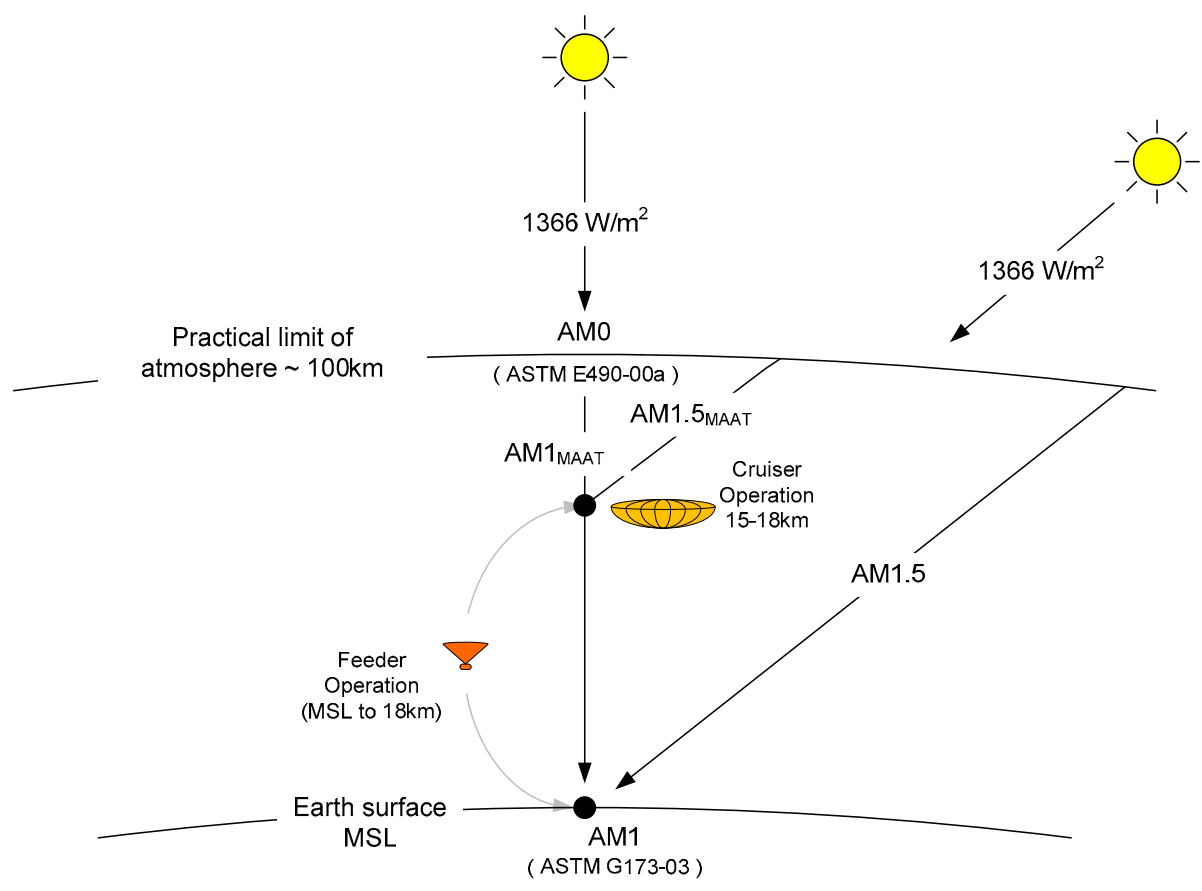

Figure 5. MAAT System operational altitude and Air Mass effect.

This, however, assumes that the spectrum is as seen at sea level. The individual extinction coefficients for each band of the wavelength given in ASTM E490 [10] needs to be calculated and the total irradiance calculated by integrating the spectral output for the relevant altitude. This, therefore, requires a modified form of Beer's law as given in Equation (3), where the extinction coefficient for each wavelength group is determined.

$$
\beta_{I N T, \lambda}=\sum\left(\beta_{e \lambda} \Delta h\right)
$$


The sun's zenith angle will also rarely be zero as it varies with both latitude and time of day as well as the earth's declination, and has also to be considered in the modified form of Beer's law, as given by the solar elevation Equation (4) below:

$$
\theta=90-\sin ^{-1}(\sin \varphi \sin \delta+\cos \varphi \cos \delta \cos \gamma) .
$$

where:

$\theta$ is the sun's zenith angle

$\varphi$ is the cruiser latitude

$\delta$ is the sun's declination

$\gamma$ is the local hour angle.

For smaller values of the sun's zenith angle $\theta$, the air mass factor is given by taking the secant of this angle; for larger values of the sun's zenith angle where $\theta$ approaches $90^{\circ}$, this clearly becomes inaccurate due to the simplification and a better approximation is given by Young [30].

\subsubsection{Harvesting Energy from the Indirect Albedo Effect}

As previously indicated, there has been significant research into global warming and the earth's total planetary albedo (reflected shortwave radiation) has been calculated as 30\% in the Global Energy Flows, Trenberth et al. [11] of the total incoming solar radiation. The remaining $70 \%$ is considered longwave radiation that is of no benefit as it is outside the spectral response of solar PV panels. The earth's average albedo, $A$, can be expressed as the sum of three terms, Fritz [31] in Equation (5):

$$
A=A_{e}+A_{a}+A_{c}
$$

where:

$A_{e}$ is the earth surface albedo

$A_{a}$ is the atmosphere

$A_{c}$ is the cloud reflection.

$A_{e}$ and $A_{a}$ are considered small compared to $A_{c}$ and its potential to provide significant additional energy for harvesting.

\section{Results}

\subsection{Available Energy from Direct Insolation}

As shown by Aglietti et al. [27], (1) and (2) can be used to determine the global mass extinction. This has now been updated with the data presented in ASTM G173 [26] and a global extinction factor of 0.278 has been applied. The results are shown in Figure 6. From a first order analysis, this shows that the available irradiance at $15 \mathrm{~km}$ to $18 \mathrm{~km}$ lies between 1323 and $1341 \mathrm{~W} / \mathrm{m}^{2}$. As stated, this is for AM1.0 $0_{\text {MAAT }}$ (caution should be exercised here as the 1.0 relates to the normalised atmosphere above the airship and not, as is usual, the normalised atmosphere above MSL).

The modified form of Beer's law (3) is now considered, and the resulting Figure 7 provides a more accurate prediction of the available direct irradiance at 15,000 m based on Equation (3). After integrating the total contribution of each wavelength group, the available irradiance is calculated to be $1220 \mathrm{Wm}^{-2}$ at $15 \mathrm{~km}, 8 \%$ lower than using the test method. The irradiance at $18 \mathrm{~km}$ is also expected to be $\sim 8 \%$ lower at $1233 \mathrm{Wm}^{-2}$ due to the absorption of some wavelengths (as shown). 


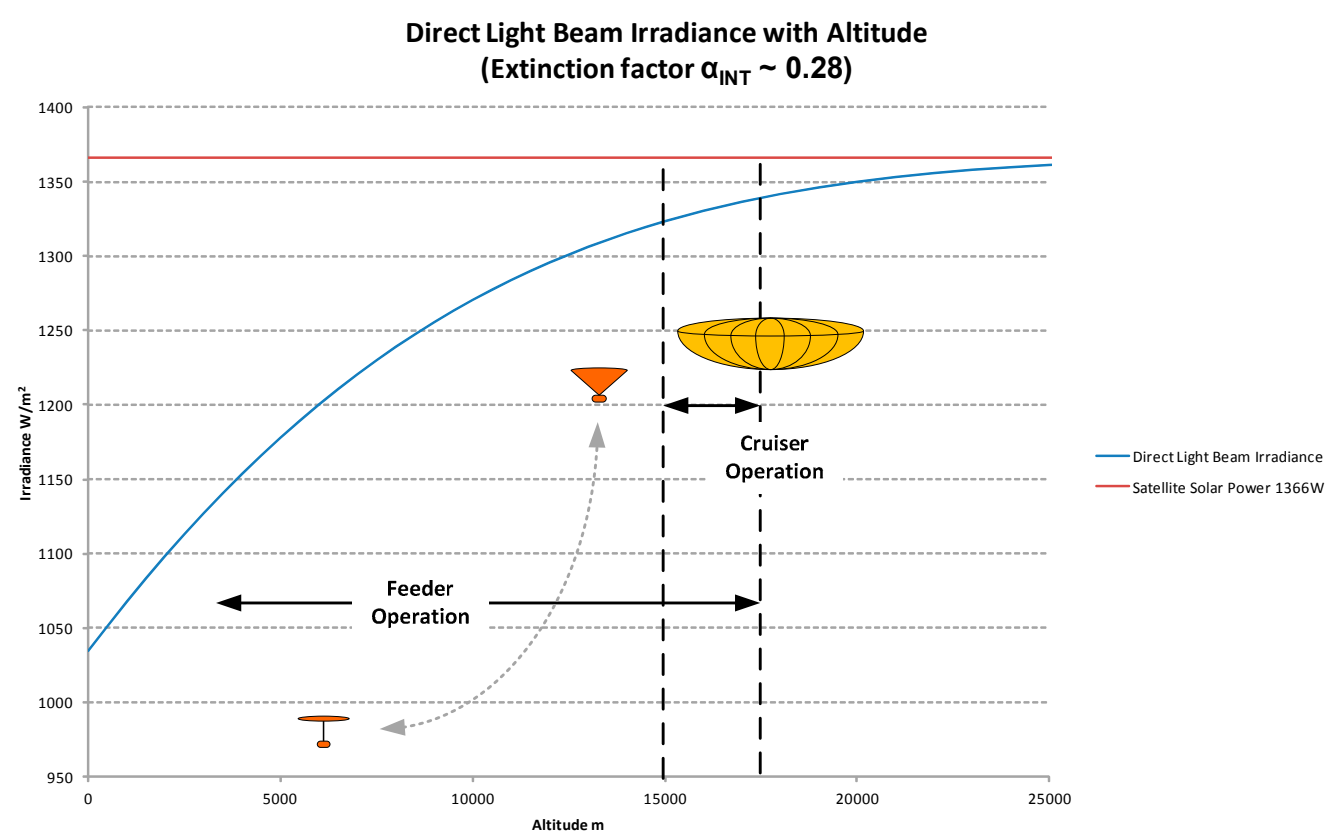

Figure 6. Variation of beam irradiance with respect to altitude at a sun zenith angle, $\theta$, of zero degrees.

Direct Spectral Irradiance for TOA, 15000m and Sea Level

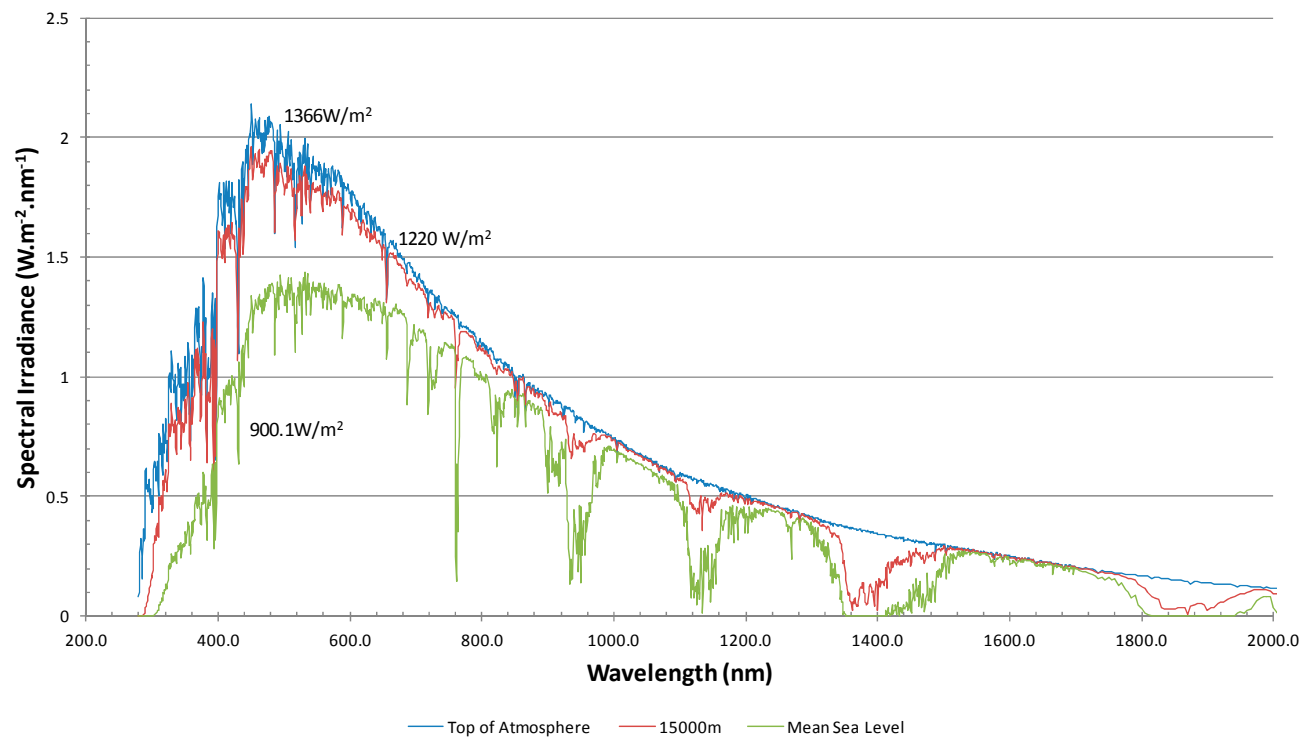

Figure 7. Direct Spectral Irradiance for TOA, 15,000 $\mathrm{m}$ and MSL.

It can be shown, Young [30], that for the sun's zenith angle of $90^{\circ}$ the air mass is 31, i.e., $\mathrm{AM} 31_{\mathrm{MAAT}}$, giving a maximum irradiation at altitudes between 15 and $18 \mathrm{~km}$ of 446 to $689 \mathrm{~W} / \mathrm{m}^{2}$. This is significantly higher than the terrestrial values for AM31 and is due to the low atmospheric pressure. As a check, the atmospheric pressure at this altitude is approximately one-fifth the pressure at sea level, which would be equivalent to a terrestrial air mass value of AM6 or zenith angle of $80^{\circ}$ and giving (from Solar Intensity reference tables [32]) an insolation of circa $470 \mathrm{Wm}^{-2}$. This significant improvement allows effective solar harvesting from sunrise to sunset for any side-mounted photovoltaics, but is obviously dependent on the final shape. 


\subsection{Available Energy from Indirect Albedo Effect}

The earth's albedo contribution $A_{\mathbf{e}}$ is relatively small (approximately $2.3 \%$ on average) compared to the atmospheric backscatter $A_{a}(6 \%)$ and cloud reflections $A_{c}(22 \%)$. In addition, studies have shown that, on average, cloud covers $50 \%$ of the earth's surface with some areas having little or no cloud cover e.g., some equatorial areas, North Africa, Australia and the Central Pacific, whilst others have between $60 \%$ and $80 \%$ cover e.g., Northern Europe and the Northern Atlantic. Other research Liou [22] has also shown that the reflected energy from some cloud types can be as high as $90 \%$ with an average of all cloud types of $65 \%$ when the solar zenith angle is $86^{\circ}$. This provides a significant contribution to the available energy for harvesting and could justify the economic cost of fully covering both the sides and under sides of MAAT or other high altitude (stratospheric) air vehicle, since these are generally operating above cloud level. Cloud type and heights vary, NASA [33], but are usually around $6 \mathrm{~km}$ but can extend up to $12 \mathrm{~km}$ and higher. Their composition is also important and the WMO classifies them into (i) high; (ii) medium; (iii) low and (iv) deep cloud types as follows:

(i) High types such as Cirrus (Ci), Cirrostratus (Cs) and Cirrocumulus (Cc) typically occur between $6 \mathrm{~km}$ and $10 \mathrm{~km}$. They are predominantly formed from ice crystals and have a low reflectivity of around $20 \%$.

(ii) Medium clouds such as Altocumulus (Ac) and Altostratus (As) occur between $2 \mathrm{~km}$ and $7 \mathrm{~km}$ and have a reflectivity of between $40 \%$ and $56 \%$.

(iii) Low cloud types such as Nimbostratus (Ns), Stratocumulus ( $\mathrm{Sc}$ ) and Cumulus (Cu) occur between $1 \mathrm{~km}$ and $2 \mathrm{~km}$ and have a reflectivity of between $60 \%$ and $70 \%$.

(iv) Deep clouds or Cumulonimbus ( $\mathrm{Cb}$ ) occur between $1 \mathrm{~km}$ and $10 \mathrm{~km}$ and have the characteristic anvil shaped head. They have the highest reflectivity typically lying between $78 \%$ and $90 \%$.

\subsection{Impact of Air Vehicle Shape}

The MAAT cruiser shape was approximated to the shape of a triaxial ellipsoid, that is, its length $(l)>$ width $(w)>$ height $(h)$ with a respective ratio of 5:3:1. It is initially assumed that the airship's upper surface will be completely covered with a photovoltaic skin which is uninterrupted by the gondola, empennage or any other systems. This is clearly an ideal condition which would not be practical in a real physical implementation. A surface utilisation factor can easily be adopted in order to reduce the available surface area based on typical PV packing factors and construction techniques such as the innovative adoption of TENSAIRITY ${ }^{\circledR}$, an air beam technology, by Sunol et al. [12], which could offer the opportunity to integrate PV, electrical connections and power transmission into a single structural component, significantly reducing copper and PV support structure masses.

When the sun rises, the projected area of the cruiser will be an ellipse, as shown in Figure 8a with its dimensions being a function of both the cruiser's dimensions and its direction of travel with respect to the direction of the sun's rays. This projected shadow area (the shadow on an orthogonal plane to the sun's rays which are parallel) represents the total amount of energy available for conversion. If the cruiser is travelling perpendicular to the sun's rays, the projected area will then be an ellipse with major radius (half the cruiser length), $a=200 \mathrm{~m}$ and a minor radius (half the depth), $b=40 \mathrm{~m}$. The area is given by the equation for the area of an ellipse, $\pi a b$, and gives a total projected area for solar collection of $25,133 \mathrm{~m}^{2}$. Similarly, when the cruiser is travelling towards or away from the sun, the area will be $15,000 \mathrm{~m}^{2}$.

In Section 3.1 the Air Mass at sunrise (or sunset) is calculated to be AM31 using Young's equation [30] at the operating altitude giving total solar insolation between $463 \mathrm{Wm}^{-2}$ and $739 \mathrm{Wm}^{-2}$ (dependent on altitude) and a total available power of $11.6 \mathrm{MW}$ at $15 \mathrm{~km}$ and $18.6 \mathrm{MW}$ at $18 \mathrm{~km}$. Similarly, the maximum available power with the sun directly overhead is $92 \mathrm{MW}$-the maximum rate of solar energy harvesting, with a minimum of $11.6 \mathrm{MW}$. With an assumed combined system efficiency of $10 \%$ (current technology), the power available to systems on board the cruiser will be between 1.2 and $9.2 \mathrm{MW}$. 
With the earth's albedo of 30\% at the TOA Donohoe [23] and Young [30], an additional $27 \mathrm{MW}$ of solar energy is available for harvesting via the lower surface.

For completeness, the proposed feeder shape is also shown in Figure 8b. It can be approximated to an inverted and cropped cone and so can also be considered as having a circular projected area when the sun is directly overhead, with a radius of $40 \mathrm{~m}$ giving a total surface area of $5027 \mathrm{~m}^{2}$. The projected shape, when the sun rises, is given approximately by a trapezium; however, with the feeder, the maximum and minimum rates of solar harvesting also depend on the altitude and that the sides are unlikely to be covered with PV as the feeder itself expands and contracts due to it being non-rigid airship. Only the canopy is fixed. At $15 \mathrm{~km}$, the available solar harvesting will be between $0 \mathrm{MW}$ and 6.1 MW. At MSL, it will be between $0 \mathrm{MW}$ and $4 \mathrm{MW}$. This, as mentioned, is due to the limited surface area available for PV and as such, the feeder will rely on its ability to "recharge" from ground-based stations.

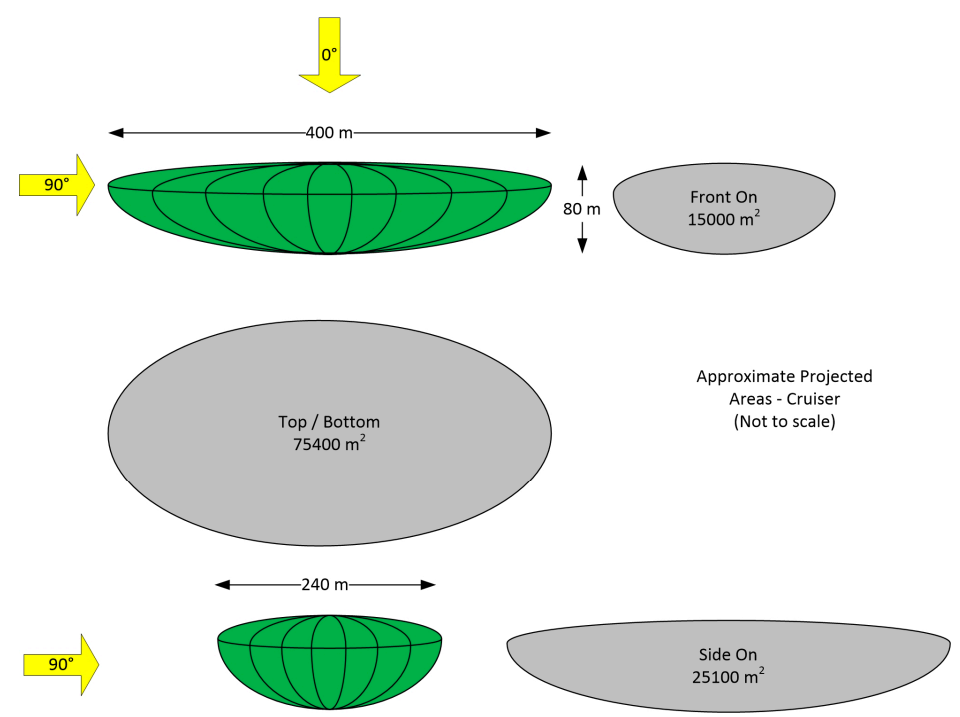

(a)

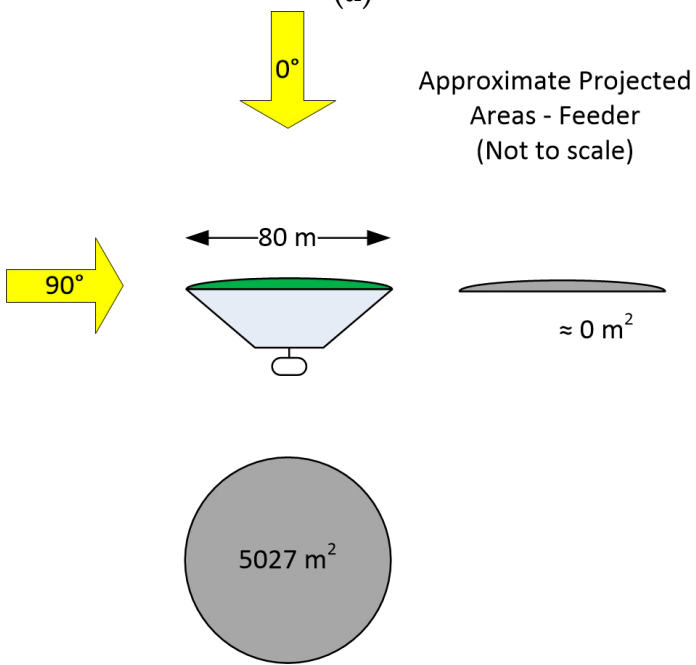

(b)

Figure 8. (a) Cruiser and (b) Feeder outline shape and projected area.

From the analysis it is evident that a substantial contribution to the overall energy harvested by the cruiser can be achieved by using the cloud albedo. However, it is crucial that technologies such as TENSAIRITY ${ }^{\mathrm{TM}}$ are exploited since it is important that the additional mass due to the under mounted photovoltaic systems does not increase the airship mass. It is also clear that the cruiser shape is critical, 
since a large flat disc would be ideally suited to solar harvesting (maximum surface area to volume); however, a spheroid shape would be more efficient static lift (minimum surface area to volume).

\section{Conclusions}

One of the major issues when using a persistent lighter than air vehicle for passenger operations at stratospheric altitudes is the associated large energy requirements and the corresponding large structure required due to both the large surface area required for PV arrays and the large volume due to the low atmospheric pressure. This conflict is further exacerbated if continuous operation is required throughout the night with an equivalent day time performance. Current technologies do not yet support the required efficiencies in power conversion and energy storage, but significant improvements are both being demanded and expected, which, when achieved, will certainly provide an opportunity for passenger services. The paper has presented initial results of an investigation into increasing the available solar energy for harvesting when applied to these new class of large high altitude airships. However, there is currently the possibility that unmanned or minimally manned (air crews only) vehicles could be used for atmospheric research, communications and surveillance platforms or as hubs for airborne delivery of support/aid packages. Such applications are very appealing as they would incur a fraction of the cost of satellites alternatives and would be accessible for both system's upgrading and maintenance. It would also be feasible to use hydrogen as both the lifting gas and principle means of energy storage. Such platforms would be smaller, requiring less propulsive power and little or no life support due to the low number of air crew. The reductions would reduce the airship's power requirements from $20 \mathrm{MW}$ to around $4 \mathrm{MW}$. Based on the power requirement, such an airship would be around $50 \%$ of the size of the current cruiser and with the utilisation of cloud albedo, should readily achieve the needed energy harvesting. Technical feasibility still requires the development of other enabling technologies, namely, higher efficiency PV's, improved energy storage systems and the application of integrated structural components such as TENSAIRITY ${ }^{\mathrm{TM}}$. Specifically, it is shown that there is the potential to increase the power generation capability of the cruiser by $50 \%$ by utilising the underside of the airship, which is only practicable in high altitude applications with operation above cloud height. Notably this is only applicable to operation in an atmosphere, since for space systems the economics are predominantly based around delivering the PV array into orbit, as there is no significant increase in energy consumption subsequently required by the platform. With the application of future PV technologies providing higher efficiencies and the prospect of using new structural techniques, e.g., TENSAIRITY ${ }^{\mathrm{TM}}$, it will be feasible to operate a manned stratospheric air vehicle, such as MAAT. Importantly, in order to minimise unnecessary increases in size to support greater solar harvesting areas, it has now also been shown that a significant contribution can be made by harvesting from cloud albedo for stratospheric operation.

Acknowledgments: Collaborators on Multibody Advance Airship for Transport MAAT Project (Seventh Framework Programme, Theme 7 Transport including Aeronautics):

- Università di Modena e Reggio Emilia (Lead)

UNIMORE Italy

- Universidade da Beira Interior

UBI

- LogisticNetwork Consultants GmbH

LNC

- The University of Hertfordshire Higher Education Corp.

$\mathrm{UH}$

- Southern Federal University

SFEDU

- Engys Ltd.

ENGYS

- Università di Bologna

UniBo

- Esponential design Lab. S.A

eDL

- Aero Sekr S.p.A

- Vrije Universiteit Brussel

- Università di Torino

ASKR

VUB

Portugal

Germany

United Kingdom

Russia

United Kingdom

Italy

Uruguay

Italy

POLITO Italy

Belgium 
Author Contributions: Tim Smith, Paul Stewart (PI), Chris Bingham (CI), Michele Trancossi, Dean Vucinic conducted the theoretical and experimental work underpinning the MAAT Energetic Systems Design. This aspect was lead and managed by the University of Lincoln.

Conflicts of Interest: The authors declare no conflict of interest.

\section{Abbreviations}

$\begin{array}{ll}\text { ASTM } & \text { American Society for Testing and Materials } \\ \text { ATEN } & \text { Aerial Transport Elevator Network (Feeder) } \\ \text { BOL } & \text { Beginning of Life } \\ \text { ECS } & \text { Environmental Control System } \\ \text { EOL } & \text { End of Life } \\ \text { FC } & \text { Fuel Cell } \\ \text { HPD } & \text { High Power Distribution } \\ \text { IFE } & \text { In Flight Entertainment } \\ \text { LPD } & \text { Low Power Distribution } \\ \text { MAAT } & \text { Multibody Advanced Airship for Transport } \\ \text { MPPT } & \text { Maximum Power Point Tracker } \\ \text { MSL } & \text { Mean Sea Level } \\ \text { PDC } & \text { Power Distribution Circuit } \\ \text { PEM } & \text { Proton Exchange Membrane } \\ \text { PUC } & \text { Primary Up Converter } \\ \text { PV (A) } & \text { Photo-voltaic (Array) } \\ \text { SAC } & \text { Solar Array Converter } \\ \text { SPP } & \text { Satellite Peak Power } \\ \text { TRU } & \text { Transformer Rectifier Unit } \\ \text { UAV } & \text { Unmanned Air Vehicle } \\ \text { UCap } & \text { Ultra Capacitor }\end{array}$

\section{References}

1. Dumas, A.; Trancossi, M. The MAAT Project, Multibody Advanced Airship for Transport, General Overview; Theme [AAT.2011.6.3.-1, AAT.2011.6.2.-1.]; Seventh Framework Programme FP7-EU-Project; LogisticNetwork Consultants GMBH: Hannover, Germany, 2011.

2. Dumas, A.; Trancossi, M.; Madonia, M.; Giuliani, I. Multibody Advanced Airship for Transport; Paper 2011-01-2786; SAE International: Toulouse, France, 2011.

3. Dumas, A.; Madonia, M.; Giuliani, I.; Trancossi, M. MAAT Cruiser Feeder Project: Criticalities and Solution Guidelines; Paper 2011-01-2784; SAE International: Toulouse, France, 2011.

4. The Tissandier Electric Airship. This Day in Aviation 8th October 1883. Available online: www. thisdayinaviation.com/tag/tissandier-electric-airship/ (accessed on 15 November 2016).

5. Khoury, G.A.; Mowforth, E. A solar airship, more than a flight of fancy. New Sci. 1978, 79, 100-102.

6. Choi, S.H.; Elliott, J.R.; King, G.C. Power Budget Analysis for High Altitude Airships. NASA Langley Research Center, Hampton, Virginia 23681-2199. Available online: ntrs.nasa.gov/archive/nasa/casi.ntrs. nasa.gov/20060012139.pdf (accessed on 15 November 2016).

7. QinetiQ News Releases after 14 Nights in the Air, QinetiQ Prepares to Land Its Zephyr Solar Powered Unmanned Aircraft 23/07/2010. Available online: www.qinetiq.com/news/Pages/news.aspx?year=2010 (accessed on 15 November 2016).

8. Solar Impulse. Available online: www.solarimpulse.com (accessed on 15 November 2016).

9. Glaser, P.E.; Maynard, O.E.; Mackovciak, J.; Ralph, E.L. Feasibility Study of a Satellite Solar Power Station; ADL-C-74830; NASA: Washington, DC, USA, 1974.

10. Standard Solar Constant and Zero Air Mass Solar Spectral Irradiance Tables; ASTM International: West Conshohocken, PA, USA, 2014.

11. Trenberth, K.E.; Fasullo, T.; Kiehl, J. Earth's global energy budget. Am. Meteorol. Soc. 2009, 311-323. [CrossRef] 
12. Sunol, A.; Vucinic, D.; De Laet, L. Tensairity concept applied to lighter-than-air vehicles for light-weight structures. In Proceedings of the ASME 2014 International Mechanical Engineering Congress and Exposition, Montreal, QC, Canada, 14-20 November 2014.

13. Dumas, A.; Trancossi, M.; Madonia, M. Energetic design and optimization of a large photovoltaic stratospheric unconventional feeder airship. SAE Int. J. Aerosp. 2012, 5, 354-370. [CrossRef]

14. Trancossi, M.; Dumas, A.; Cimarelli, A.; Pascoa, J. MAAT cruiser/feeder airship design: Intrinsic stability and energetic flight model. In Proceedings of the ASME 2015 International Mechanical Engineering Congress and Exposition, Houston, TX, USA, 13-19 November 2015.

15. Pallett, E.H.J. Aircraft Electrical Systems, 3rd ed.; Longman Scientific and Technical: Harlow, UK, 1987.

16. Majeed, O. Aircraft Environmental Control Systems; Carleton University Aero Lecture 4003: Ottawa, ON, USA, 2010.

17. Massive 787 System Pressurises Cabin. Available online: http://aviationweek.com/awin/massive-787electrical-system-pressurizes-cabin (accessed on 12 April 2016).

18. KIDSysteme, Technical Data Sky Power. System/Airbus. Available online: http://www.kid-systeme.de/ (accessed on 12 April 2016).

19. Burke, K.A. Unitized regenerative fuel cell system development. In Proceedings of the 1st International Energy Conversion Engineering Conference (IECEC), Portsmouth, VA, USA, 17-21 August 2003.

20. NREL Best Research Cell Efficiencies. Available online: https://en.wikipedia.org/wiki/Solar_cell_efficiency (accessed on 15 November 2016).

21. Smith, T.; Bingham, C.; Stewart, P.; Allarton, R.; Stewart, J. Energy harvesting and power network architectures for the multibody advanced airship for transport high altitude cruiser-feeder airship concept. J. Aerosp. Eng. 2013. [CrossRef]

22. Liou, K.-N. On the absorption, reflection and transmission of solar radiation in cloudy atmospheres. J. Atmosp. Sci. 1976, 33, 798-805. [CrossRef]

23. Donohoe, A.; Battisti, D.S. Atmospheric and surface contributions to planetary albedo. J. Clim. 2011, 24, 4402-4417. [CrossRef]

24. Blumthaler, M.; Ambach, W.; Ellinger, R. Increase in solar radiation with altitude. J. Photochem. Photobiol. 1997, 39, 130-134. [CrossRef]

25. Dumas, A.; Trancossi, M.; Madonia, M.; Anzillotti, S. Effects of altitude on photovoltaic production of hydrogen. In Proceedings of the 5th International Conference on Energy Sustainability, Washignton, DC, USA, 7-10 August 2011; pp. 1-10.

26. Standard Tables for Reference Solar Spectral Irradiances: Direct Normal and Hemispherical on $37^{\circ}$ Tilted Surface; ASTM G173-03(2012); ASTM International: West Conshohocken, PA, USA, 2012.

27. Liou, K.N. An Introduction to Atmospheric Radiation (International Geophysics Series), 2nd ed.; Academic: San Diego, CA, USA, 2002; Volume 84.

28. Rapp-Arraras, I.; Domingo-Santos, M. Extinction, refraction, and delay in the atmosphere. J. Geophys. Res. 2008, 113. [CrossRef]

29. Aglietti, G.; Redi, S.; Tatnall, A.; Markvart, T. Harnessing high-altitude solar power. IEEE Trans. Energy Convers. 2009, 24, 442-451. [CrossRef]

30. Young, T. Air mass and refraction. Appl. Opt. 1994, 33, 1108-1110. [CrossRef] [PubMed]

31. Fritz, S. The albedo of the planet earth and of clouds. J. Metrol. 1949, 6, 277-282. [CrossRef]

32. Solar Intensity versus AM Coefficient. Available online: https://en.wikipedia.org/wiki/Air_mass_(solar_ energy) (accessed on 15 November 2016).

33. National Aeronautics and Space Administration. The Earth Science Enterprise Series—Clouds and the Energy Cycle NF-207; Goddard Space Flight Center: Greenbelt, MD, USA, 2017.

(C) 2017 by the authors. Licensee MDPI, Basel, Switzerland. This article is an open access article distributed under the terms and conditions of the Creative Commons Attribution (CC BY) license (http:/ / creativecommons.org/licenses/by/4.0/). 